\title{
Efficient Tandem Organic Light Emitting Diode Using Organic Photovoltaic Charge Generation Layer
}

\author{
Akanksha Jetly (D) and Rajesh Mehra \\ Electronics and Communication Department, NITTTR, Chandigarh, India \\ Correspondence should be addressed to Akanksha Jetly; akankshajetly@yahoo.com
}

Received 9 June 2018; Accepted 20 August 2018; Published 26 September 2018

Academic Editor: Sulaiman W. Harun

Copyright (C) 2018 Akanksha Jetly and Rajesh Mehra. This is an open access article distributed under the Creative Commons Attribution License, which permits unrestricted use, distribution, and reproduction in any medium, provided the original work is properly cited.

\begin{abstract}
Highly efficient tandem red OLED is proposed using planar organic heterojunction based charge generation layer (CGL) of C70 (Fullerene)/CoPc (Cobalt Phthalocyanine). The proposed charge generation layer generates charges and exhibits organic photovoltaic type (OPV) behavior in the red emitter zone which helps in slower efficiency roll-off at higher current densities. In addition an ultrathin layer of $\mathrm{Al} / \mathrm{LiF}$ is used as electron injection layer (EIL) so as to enhance the injection of electrons from charge generation layer to emissive unit. It is found that the tandem red device can reach current efficiency and luminance of $26 \mathrm{~cd} / \mathrm{A}$ and $26039 \mathrm{~cd} / \mathrm{m}^{2}$ at $20 \mathrm{~mA} / \mathrm{cm}^{2}$ and $100 \mathrm{~mA} / \mathrm{cm}^{2}$, respectively, which is 1.663 times and 1.665 times higher than the corresponding single emitter device. Moreover, it is known that the tandem device requires double turn-on voltage than conventional devices. In this work, the turn-on voltage of red tandem device $(5.85 \mathrm{~V})$ is found to be less than twice the voltage of conventional device $(3 \mathrm{~V})$. Further with the introduction of Distributed Bragg Reflector (DBR), enhancement in current efficiency and brightness of tandem red device are observed due to high reflectance property of DBR. Thus, the effective charge generation and OPV function of proposed charge generation layer as well as remarkably high injection property of EIL layer lead to the high performance tandem OLED.
\end{abstract}

\section{Introduction}

Developed in 1987 and based on the electroluminescent phenomenon, organic light emitting diodes have turned out to be a blessing for both display and lightning applications because of their ability to produce more vibrant colors and amazing features like low operating voltage, wide viewing angle, low power consumption, flexibility, thin, light weight, high resolution, and many more. The basic OLED structure comprises of electroluminescent unit that contains anode and cathode and emitting and transport layers between these electrodes. The light is generated in the emitting layer upon the application of external supply because of the radiative recombination of electrons and holes injected by the electrodes. To make the conventional OLEDs more efficient, the theory of tandem OLED was demonstrated in the year 2003. Tandem OLED is an advancement of basic OLED structure that comprises of two or more electroluminescent units that are placed one over the other and are separated by the interconnecting or charge generation (CGL) layer. They have the potential to achieve higher efficiency and luminance at minuscule current density with the increase in the number of electroluminescent units. They have longer lifespan in contrast to the conventional OLEDs as they have the tendency to reduce efficiency roll-off caused by the higher current density.

The enhanced performance of tandem OLED is attributed to the charge generation layer which serves exactly like the heart of tandem OLEDs. As a fundamental interconnector in tandem OLEDs, CGLs must have high transparency, low electrical resistance, matched HOMO LUMO levels with the adjacent transport layers, low power loss, etc. When the external voltage is supplied, charge carriers are generated in the CGL, which are then injected into the neighboring emitting unit via the transport layers, where they combine with the opposite charges injected by the electrodes to generate light. 
TABLE 1: The detail device structures of red and blue OLEDs.

\begin{tabular}{lcc}
\hline Device & Device Name & Layer Structure \\
\hline Red conventional OLED & $\mathrm{A}$ & $\mathrm{ITO} / \mathrm{EL} / \mathrm{LiF}(2 \mathrm{~nm}) / \mathrm{Al}(150 \mathrm{~nm})$ \\
Red Tandem OLED & $\mathrm{R}$ & ITO/EL/CGL/EL $/ \mathrm{LiF}(2 \mathrm{~nm}) / \mathrm{Al}(150 \mathrm{~nm})$ \\
Blue conventional OLED & $\mathrm{B} 1$ & ITO/EL $1 / \mathrm{LiF}(2 \mathrm{~nm}) / \mathrm{Al}(150 \mathrm{~nm})$ \\
Blue Tandem OLED & $\mathrm{B} 2$ & ITO/EL $1 / \mathrm{CGL} / \mathrm{EL} 1 / \mathrm{LiF}(2 \mathrm{~nm}) / \mathrm{Al}(150 \mathrm{~nm})$ \\
\hline
\end{tabular}

EL: $\mathrm{MoO}_{3}(3 \mathrm{~nm}) / \mathrm{NPB}(40 \mathrm{~nm}) / \alpha$-NPD: $\operatorname{Ir}(\text { piq })_{3}(30 \mathrm{~nm}, 20 \%$ by volume $) /$ Bphen $(30 \mathrm{~nm})$.

EL 1: $\mathrm{MoO}_{3}(3 \mathrm{~nm}) / \mathrm{NPB}(40 \mathrm{~nm}) / \mathrm{sDPVBi}(30 \mathrm{~nm}) /$ Bphen $(30 \mathrm{~nm})$.

CGL: $\mathrm{Al}(3 \mathrm{~nm}) / \mathrm{LiF}(2 \mathrm{~nm}) / \mathrm{C} 70(5 \mathrm{~nm}) / \mathrm{CoPc}(5 \mathrm{~nm})$.

The CGL is typically a $\mathrm{p}-\mathrm{n}$ junction that consists of metal/metal or metal oxide/metal oxide bilayer structure, organic doped n-type layer/p-type layer, or organic photovoltaic heterojunctions. Out of these, CGLs comprising metal layers or metal oxide layers are comparatively less transparent and electrically more resistant as they can easily react with dopants present in the adjacent transport layer to form complexes, thus enhancing the driving voltage and degrading the performance of the device. Further in OLEDs because of the waveguide modes, surface plasmon, and optical losses, the $75-80 \%$ of the total produced light is lost; only $20-25 \%$ of the persisting light can be efficiently drawn out of device. Thus, for enhancing the efficiency and performance of device, it becomes very necessary to utilize that lost part of light. To surpass all these limitations organic photovoltaic (OPV) type interconnectors formed of the organic materials with the low energy gap are mostly used $[1,2]$.

They have the tendency to generate the charges called electrically generated charges upon the application of external voltage and they have the additional advantage of absorbing a fraction of wasted photons (packets of light energy) from the emissive layer to form the excitons and then at the interface of heterojunction separates them into free electrons and holes. These free electrons and holes are known as photo generated charges. Thus, due to their unique feature of producing photo as well as electric generated charges, this OPV heterojunctions are contemplated as very efficient interconnectors in tandem OLEDs. In this work, the conjunction of organic fullerene derivative $\mathrm{C} 70$ and $\mathrm{CoPc}$ (Cobalt Phthalocyanine) heterojunction is proposed as planar charge generation layer of tandem OLEDs, where C70 behaves as ntype semiconductor material that has high thermal stability with exceptionally high electrons mobility and CoPc acts as p-type semiconductor material that has high holes' mobility. Further, to boost up the injections of electrons from the CGL to the neighboring emitting unit, the combination of thin layers of $\mathrm{Al}$ (aluminium) along with $\mathrm{LiF}$ (Lithium Fluoride) is used as electron injection material. The advantage of using aluminium is that it helps in decreasing the work function of C70, thus increasing the device performance.

\section{Materials and Methods}

In this work, the CGL comprises the multilayers of $\mathrm{Al} / \mathrm{LiF} / \mathrm{C} 70 / \mathrm{CoPc}$. The coalition of $\mathrm{C} 70 / \mathrm{CoPc}$ acts as the planar organic heterojunction at which the charges are generated whereas the $\mathrm{Al} / \mathrm{LiF}$ works as the effective electron injection layer that helps in enhancing the injection of electrons from CGL to the adjacent emitting units. To exhibit the efficacy of the proposed CGL, various devices are designed and simulated. The detail device structures are given in Table 1. The Schematic diagram of tandem device $\mathrm{R}$ is shown in Figure 1. In these devices ITO (Indium Tin Oxide) and $\mathrm{Al} / \mathrm{LiF}$ act as anode and cathode, respectively, NPB (N,N0-bis-(3-naphthy)-N,N'-biphenyl-(1,1'-biphenyl)$4,4^{\prime}$-diamine) as the hole transport layer, and Bphen(4,7diphenyl-1,10-phenanthroline) as electron transport layer in the two electroluminescent units. To prove the OPV behavior of the proposed CGL, red and blue devices are designed as given in Table 1 using $\alpha$-NPD (N, $N^{\prime}$-Bis(naphthalen-1-yl)$\mathrm{N}, \mathrm{N}^{\prime}$-bis(phenyl)-2,2-diMe) as host material for red emitter $\operatorname{Ir}(\text { piq })_{3}$ (Tris [1-phenylisoquinoline- $\mathrm{C}^{2}, \mathrm{~N}$ ] iridium(III)) and sDPVBi $\left(4,4^{\prime}\right.$-bis $\left(2,2^{\prime}\right.$-diphenylvinyl)-1,1' - spirobiphenyl as blue emitting material. The transport layers and electrodes optical constants are drawn from the [1]. The device emitting area is kept at $3 \mathrm{~mm} \mathrm{X} 3 \mathrm{~mm}$ and the temperature is kept at $290 \mathrm{~K}$ for this work. The Fluxim Setfos 4.6 is used to study the electrical and optical properties of the device.

To prove the efficacy of proposed OPV planar heterojunction and the ultrathin electron injection layer $(\mathrm{Al} / \mathrm{LiF})$, the conventional single emitter device structure is kept the same as used in [1] except that of the emitter that was CBP: $\operatorname{Ir}\left(\right.$ piq) ${ }_{2}$ acac ( $8 \%$ by volume). Due to the simulations environment limitation, the emitter used in this work is $\alpha$ NPD: $\operatorname{Ir}(\mathrm{piq})_{3}(20 \%$ by volume). However, the emitting zone and the peak wavelength of $\alpha$-NPD: $\operatorname{Ir}(\text { piq })_{3}$ are the same as that of CBP: $\operatorname{Ir}(\text { piq })_{2}$ acac. Both the emitters emit in the red wavelength zone of $600-800 \mathrm{~nm}$ and have peak wavelength around $625 \mathrm{~nm}$. The charge generation layer used in [1] comprised the multilayers of LiF/C60 (Fullerene Derivative 60) / CuPc (copper phthalocyanine) $/ \mathrm{MoO}_{3}$, where $\mathrm{C} 60 / \mathrm{CuPc}$ exhibits the organic photovoltaic type behavior and $\mathrm{LiF}$ and $\mathrm{MoO}_{3}$ are the interface layers that increase the injection of charge carriers from CGL to the emissive layer.

\section{Results and Discussion}

The capacitance versus voltage plot as known from the former studies is the most suitable method to designate that the free positive and negative charge pairs are produced at the interface of the proposed organic heterojunction [3-5]. For this purpose, three devices D1-D3 is designed and simulated. 


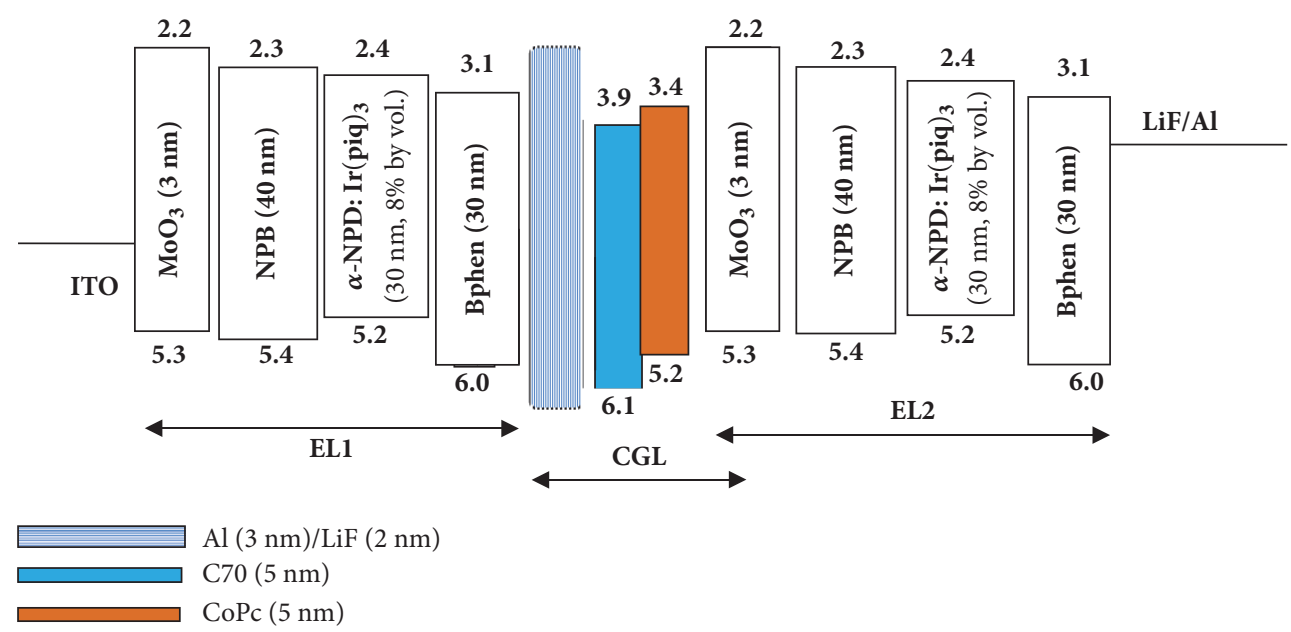

FIgURE 1: Structure of device R.

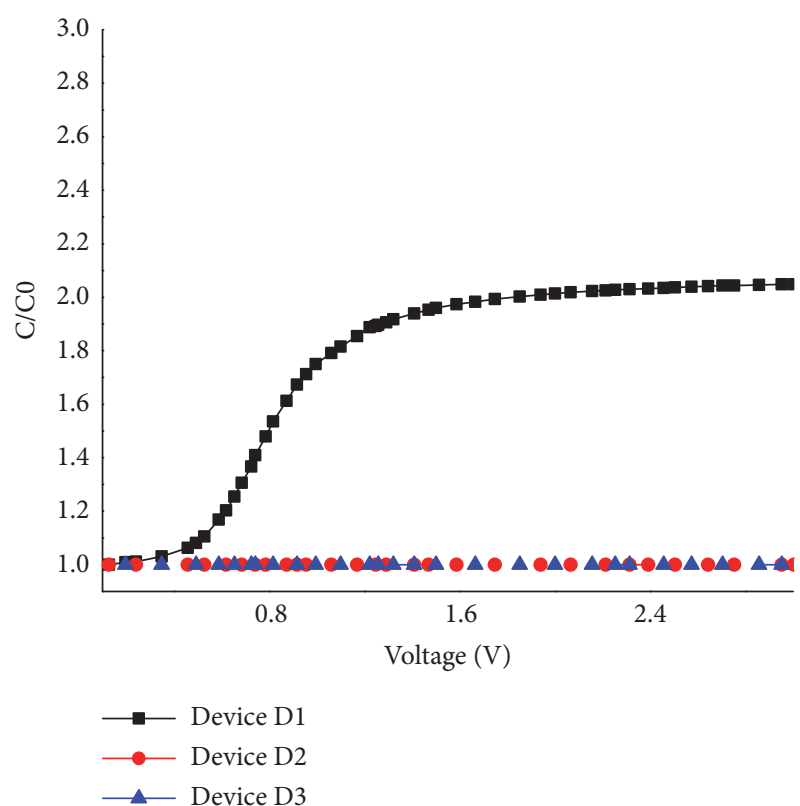

FIGURE 2: CV characteristics of devices D1, D2, and D3.

The detail structure of the all the three devices is summarized in Table 2. To block the injection of holes and electrons from electrodes thick layers of $\mathrm{LiF}(50 \mathrm{~nm})$ and $\mathrm{MoO}_{3}(50 \mathrm{~nm})$ are used alongside anode and cathode, respectively. As can be seen from Figure 2 that, with the increase in the external voltage, the capacitance also increases for device D1 whereas for the devices D2 and D3, the capacitance remains invariable with the voltage. The rise in capacitance with voltage of device D1 should be attributed to the production of free charges at the interface of the proposed organic heterojunction of $\mathrm{C} 70 / \mathrm{CoPc}$ because charge carriers from the electrodes are blocked by the thick insulating layers of $\mathrm{LiF}$ and $\mathrm{MoO}_{3}$.

To show further the charge generation capability of $\mathrm{C} 70$ / CoPc based planar heterojunction, a current limited device

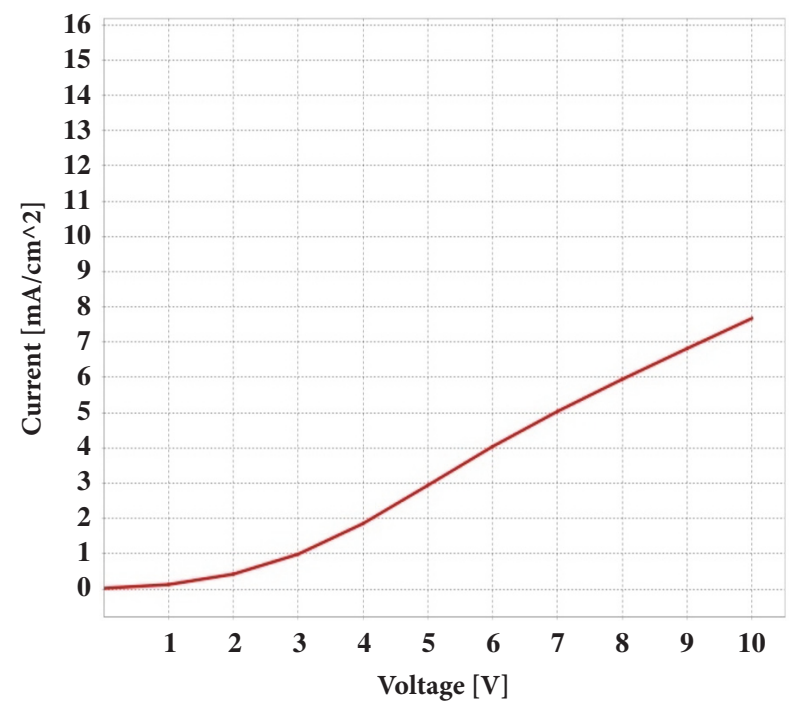

Figure 3: JV plot of device C.

is fabricated. The detail structure of device $\mathrm{C}$ is summarized as follows: ITO $(100 \mathrm{~nm}) / \mathrm{LiF}(50 \mathrm{~nm}) / \mathrm{C} 70(5 \mathrm{~nm}) / \mathrm{CoPc}$ $(5 \mathrm{~nm}) / \mathrm{MoO}_{3}(50 \mathrm{~nm}) / \mathrm{Al}(150 \mathrm{~nm})$. Here the $50 \mathrm{~nm}$ thick layers of $\mathrm{LiF}$ and $\mathrm{MoO}_{3}$ act as the holes and electrons blocking layers, respectively, that blocks the injection of holes and electrons from the two electrodes. It means that, as shown in Figure 3, the current in the current limited device is only because of the production of charge carriers at the $\mathrm{C} 70 / \mathrm{CoPc}$ interface because the injection of charge carriers from the two electrodes are blocked by the thick blocking layers. The whole operating process of the device is shown in Figure 4. On application of voltage, the large amount of charges are produced at the $\mathrm{C} 70 / \mathrm{CoPc}$ interface, which moves towards the electrodes from the interface, which are then collected by the electrodes, exhibiting unique diode behavior in the device. So, JV characteristics is one of the most appropriate methods to depict the charge generation ability of the charge generation layer. 
TABLE 2: C-V characteristics of three devices D1, D2, and D3.

\begin{tabular}{lc}
\hline Device & Layer Structure \\
\hline D1 & $\mathrm{ITO} / \mathrm{LiF}(50 \mathrm{~nm}) / \mathrm{C} 70(5 \mathrm{~nm}) / \mathrm{CoPc}(5 \mathrm{~nm}) / \mathrm{MoO}(50 \mathrm{~nm}) / \mathrm{Al}(150 \mathrm{~nm})$ \\
D2 & $\mathrm{ITO} / \mathrm{LiF}(50 \mathrm{~nm}) / \mathrm{C} 70(5 \mathrm{~nm}) / \mathrm{NPB}(5 \mathrm{~nm}) / \mathrm{MoO}_{3}(50 \mathrm{~nm}) / \mathrm{Al}(150 \mathrm{~nm})$ \\
D3 & $\mathrm{ITO} / \mathrm{LiF}(50 \mathrm{~nm}) / \mathrm{Bphen}(5 \mathrm{~nm}) / \mathrm{CoPc}(5 \mathrm{~nm}) / \mathrm{MoO}_{3}(50 \mathrm{~nm}) / \mathrm{Al}(150 \mathrm{~nm})$ \\
\hline
\end{tabular}

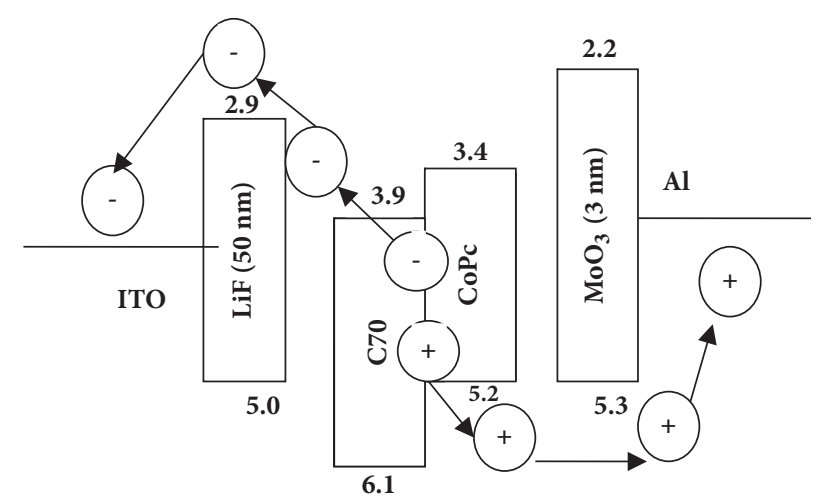

Figure 4: Operating process of device C.

The energy level alignment of CGL with the adjacent transport layers is depicted in Figure 1. It can be seen that the HOMO (highest occupied molecular orbit) level difference between NPB $(5.4 \mathrm{eV})$ and $\mathrm{CoPc}(5.2 \mathrm{eV})$ is only $0.2 \mathrm{eV}$ and LUMO (lowest unoccupied molecular orbit) level difference between $\mathrm{C} 70(3.9 \mathrm{eV})$ and Bphen $(3.1 \mathrm{eV})$ is $0.8 \mathrm{eV}$. Due to the small energy level difference between CGL and the neighboring transport layers, free charge carriers are produced at the interface of $\mathrm{C} 70 / \mathrm{CoPc}$ planar heterojunction and transfer to the adjacent emitting layers i.e., holes can easily transfer from HOMO of CoPc to that of NPB while electrons can easily jump from LUMO of C70 to that of Bphen. Then from HOMO of NPB and LUMO of Bphen, the holes and electrons can move easily to the adjacent emitting units where they combine with the opposite charge carriers injected by the electrodes to form photons.

The optical and electrical properties are used to study the effect of thickness variation of CGL on the behavior of the device. The effect of thickness variation of CGL on the optical properties is studied by calculating the transmittance for different thickness of $\mathrm{C} 70 / \mathrm{CoPc}$ from the absorption spectra as shown in Figure 5 by using the formula Transmittance $=$ antilog (2-absorption). Thus, transmittance is calculated to be $94.5 \%, 84.62 \%$, and $71.56 \%$, respectively, for $5 \mathrm{~nm}, 10 \mathrm{~nm}$, and $15 \mathrm{~nm}$ thickness of both C70 and CoPc while for $5 \mathrm{~nm}$ thickness of C70 and $10 \mathrm{~nm}$ thickness of CoPc, transmittance is $90.28 \%$ and for $10 \mathrm{~nm}$ thickness of C70 and $5 \mathrm{~nm}$ thickness of CoPc, transmittance is $84.62 \%$ at $625 \mathrm{~nm}$. Thus, the planar organic heterojunction displays the highest transmittance for $5 \mathrm{~nm}$ thickness of both C70 and CoPc.

The effect of thickness variation of CGL on the electrical properties is studied by observing the current density versus voltage plot of different thickness of C70/CoPc. A test device $\mathrm{T}$ with the structure of ITO/Bphen $(30 \mathrm{~nm}) / \mathrm{Al}(3 \mathrm{~nm}) / \mathrm{LiF}$ $(2 \mathrm{~nm}) / \mathrm{C70}(\mathrm{x} \mathrm{nm}) / \mathrm{CoPc}(\mathrm{y} n \mathrm{~nm}) / \mathrm{NPB}(40 \mathrm{~nm}) / \mathrm{Al}$ is

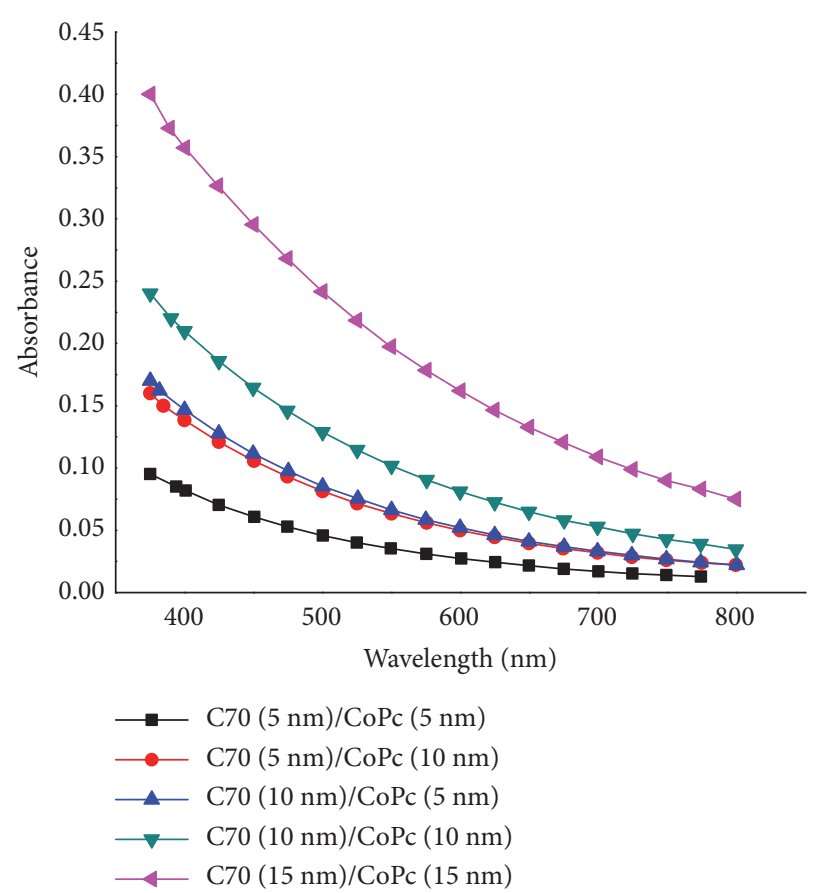

FIgURE 5: Absorbance plot of CGL at various thicknesses.

designed and simulated for this purpose. The voltages at $200 \mathrm{~mA} / \mathrm{cm}^{2}$ are noted for different thickness sets of $\mathrm{x}$ and $\mathrm{y}$ $(\mathrm{x}, \mathrm{y})$. From Figure 6, it is found that voltages are $12.45 \mathrm{~V}, 13.3$ $\mathrm{V}, 13.4 \mathrm{~V}, 14.4 \mathrm{~V}$, and $16.46 \mathrm{~V}$, respectively, for thickness sets $(5 \mathrm{~nm}, 5 \mathrm{~nm}),(5 \mathrm{~nm}, 10 \mathrm{~nm}),(10 \mathrm{~nm}, 5 \mathrm{~nm}),(10 \mathrm{~nm}, 10 \mathrm{~nm})$, and $(15 \mathrm{~nm}, 15 \mathrm{~nm})$. Thus the minimum voltage is found for $5 \mathrm{~nm}$ thickness of both C70 and CoPc for the same current density. Thus, it can be noted that increasing the thickness of CGL causes the difficulty in electron extraction from CGL. That is why, more voltage is required to extract the electrons at same current density with the increasing thickness $[6,7]$. Therefore, the optimized thickness of both C70 and CoPc is found to be $5 \mathrm{~nm}$ from both the electrical and optical properties.

Further, tandem devices T1-T4 made with distinct interconnectors are designed and simulated to prove the effectiveness of proposed CGL consisting of multilayers of $\mathrm{Al} / \mathrm{LiF} / \mathrm{C} 70 / \mathrm{CoPc}$ and also the advantage of using $\mathrm{C} 70$ over C60. The detail design structure of devices T1-T4 is given in Table 3. It can be shown from the current efficiency and luminance plots of devices T1-T4 and device A and R as given in Figures 7 and 8, respectively, that, out of all the devices given in Table 3, the red tandem device $\mathrm{R}$ with CGL layer consisting of $\mathrm{Al} / \mathrm{LiF} / \mathrm{C} 70 / \mathrm{CoPc}$ shows the best performance in terms of current efficiency and luminance with respect to 
TABLE 3: Detailed layer structures of red tandem OLED with different interconnectors.

\begin{tabular}{lc}
\hline Device & Layer Structure \\
\hline T1 & ITO/EL/IC $1 / \mathrm{EL} / \mathrm{LiF}(2 \mathrm{~nm}) / \mathrm{Al}(150 \mathrm{~nm})$ \\
T2 & ITO/EL/IC $2 / \mathrm{EL} / \mathrm{LiF}(2 \mathrm{~nm}) / \mathrm{Al}(150 \mathrm{~nm})$ \\
T3 & ITO/EL/IC $3 / \mathrm{EL} / \mathrm{LiF}(2 \mathrm{~nm}) / \mathrm{Al}(150 \mathrm{~nm})$ \\
T4 & $\mathrm{ITO} / \mathrm{EL} / \mathrm{IC} 4 / \mathrm{EL} / \mathrm{LiF}(2 \mathrm{~nm}) / \mathrm{Al}(150 \mathrm{~nm})$ \\
\hline
\end{tabular}

EL: $\mathrm{MoO}_{3}(3 \mathrm{~nm}) / \mathrm{NPB}(40 \mathrm{~nm}) / \alpha$-NPD: $\operatorname{Ir}(\mathrm{piq})_{3}(30 \mathrm{~nm}, 20 \%$ by volume $) /$ Bphen $(30 \mathrm{~nm})$.

IC 1: $\mathrm{C} 70(5 \mathrm{~nm}) / \mathrm{CoPc}(5 \mathrm{~nm})$.

IC 2: $\operatorname{LiF}(2 \mathrm{~nm}) / \mathrm{C} 70(5 \mathrm{~nm}) / \operatorname{CoPc}(5 \mathrm{~nm})$.

IC 3: $\mathrm{Al}(3 \mathrm{~nm}) / \mathrm{C} 70(5 \mathrm{~nm}) /$ Pentacene $(5 \mathrm{~nm})$.

IC 4: $\mathrm{Al}(3 \mathrm{~nm}) / \mathrm{LiF}(2 \mathrm{~nm}) / \mathrm{C} 60(5 \mathrm{~nm}) / \mathrm{CoPc}(5 \mathrm{~nm})$.

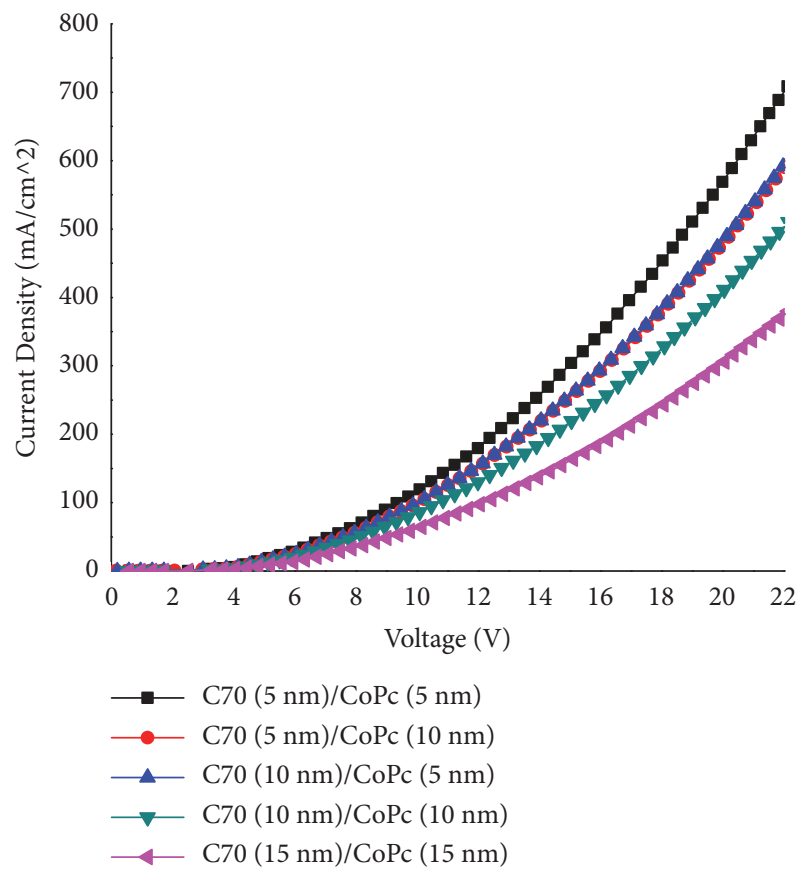

FIGURE 6: JV plot of CGL at various thicknesses.

single emitter device A. The current efficiencies of device T1$\mathrm{T} 4$ and device R, respectively, are found to be $16.97,17.21$, $25.65,25.37$, and $26 \mathrm{~cd} / \mathrm{A}$ at $20 \mathrm{~mA} / \mathrm{cm}^{2}$ and luminance is $16970,17217,25660,25378$, and $26039 \mathrm{~cd} / \mathrm{m}^{2}$ at $100 \mathrm{~mA} / \mathrm{cm}^{2}$. It can be observed that the device R exhibits almost two times enhanced current efficiency and luminance in contrast to device $A\left(15.63 \mathrm{~cd} / \mathrm{A}\right.$ and $\left.15,630 \mathrm{~cd} / \mathrm{m}^{2}\right)$.

This enhanced performance can be attributed to the interface layer or injection layer used with CGL which are crucial because of their functional efficacy and excellent charge injection property which eventually causes carrier recombination and balance in the emitting layer and also to the large energy level alignment between CoPc and C70 as well as good transport ability of C70 than that of C60. The HOMO of CoPc is $5.2 \mathrm{eV}$ and LUMO of C60 is $3.7 \mathrm{eV}$ whereas that of $\mathrm{C} 70$ is $3.9 \mathrm{eV}$. Therefore electrons have to cross a large energy barrier of $1.5 \mathrm{eV}$ to jump to LUMO of C60 from the HOMO of $\mathrm{CoPc}$ in contrast to $\mathrm{C} 70 / \mathrm{CoPc}$ where

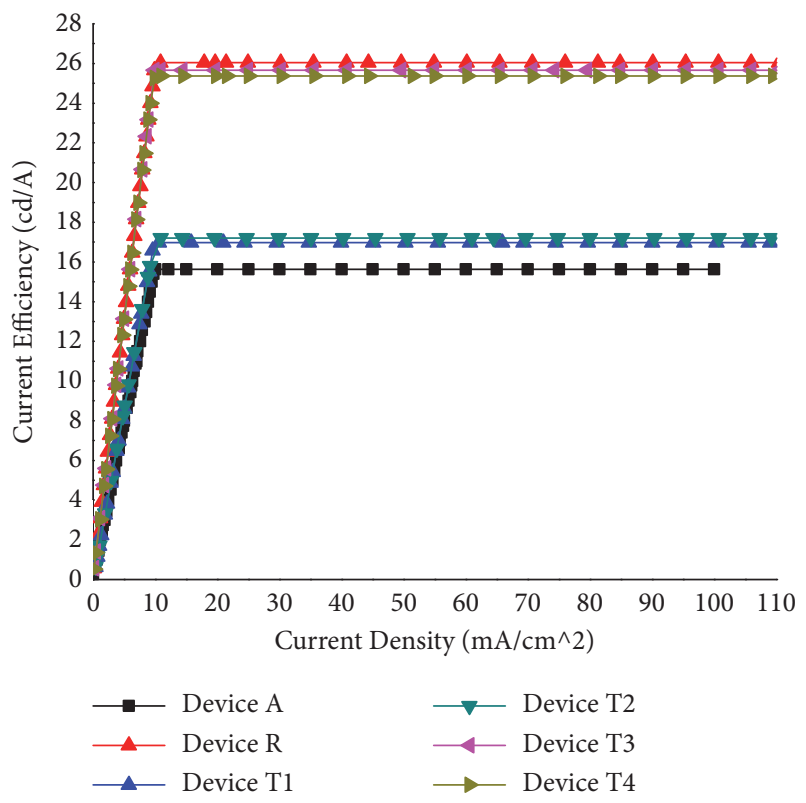

Figure 7: Current efficiency plot of various devices.

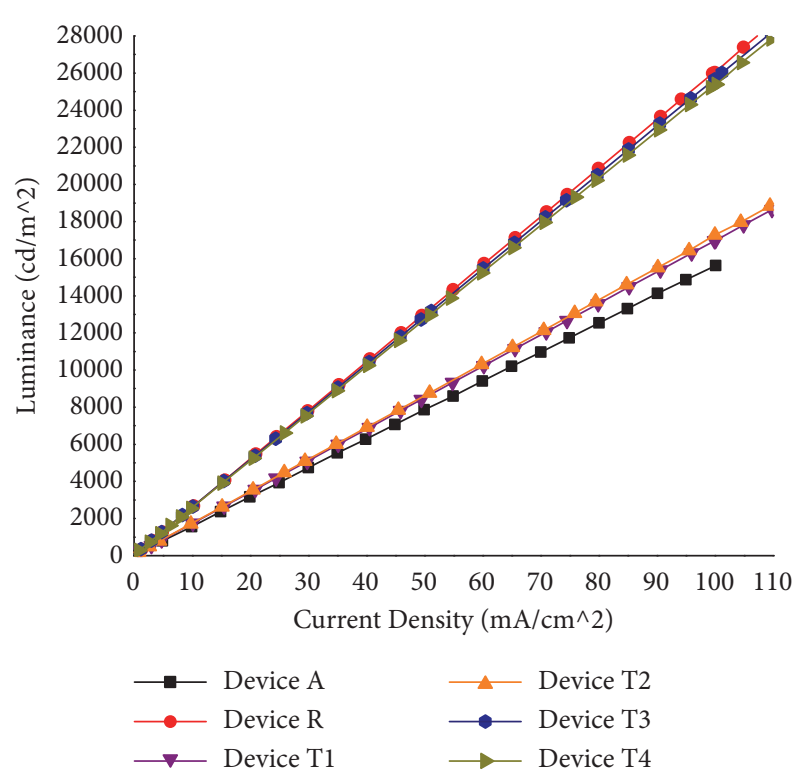

Figure 8: Luminance plot of various devices. 
TABLE 4: Comparison of proposed devices with the corresponding devices used in [1].

\begin{tabular}{lcccc}
\hline Parameters & $\begin{array}{c}\text { Red Single Emitter } \\
\text { Device A }\end{array}$ & $\begin{array}{c}\text { Red Single Emitter } \\
\text { Device [1] }\end{array}$ & Red Tandem Device R & Red Tandem Device [1] \\
\hline Current Efficiency (cd/A) @ 20 & 15.63 & 8 & 26 & 17 \\
$\mathrm{~mA} / \mathrm{cm}^{2}$ & 15630 & 7593 & 26039 & 16061 \\
Luminance $\left(\mathrm{cd} / \mathrm{m}^{2}\right) @ 100 \mathrm{~mA} / \mathrm{cm}^{2}$ & 17.9 & 8.8 & 29.3 & 14.1 \\
EQE @ $1000 \mathrm{~cd} / \mathrm{m}^{2}$ & & & \\
\hline
\end{tabular}

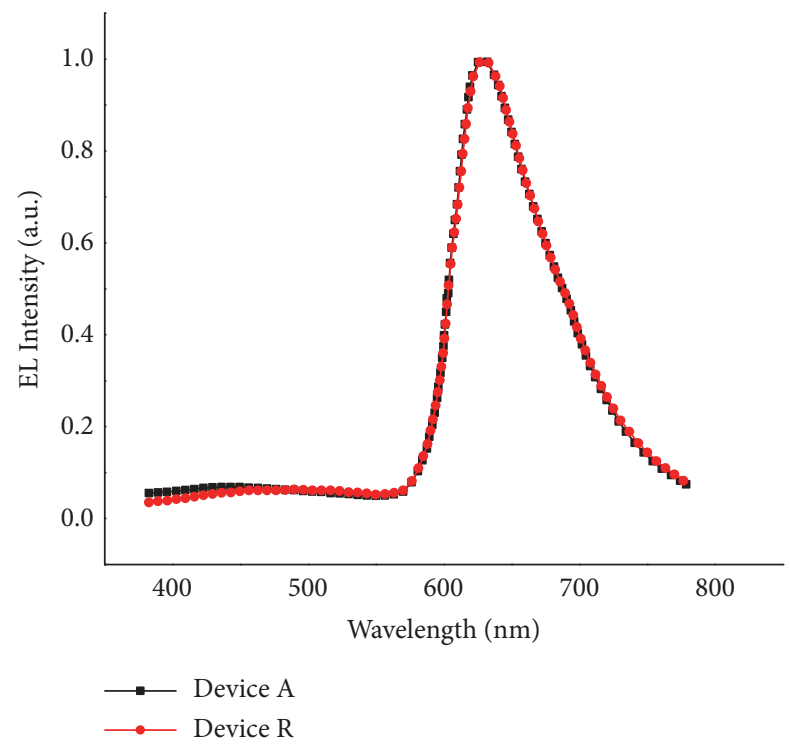

Figure 9: EL spectra of devices A and R.

the energy barrier is $1.3 \mathrm{eV}$. Thus $\mathrm{C} 70 / \mathrm{CoPc}$ heterojunction is highly efficient than the C60/CoPc heterojunction [8].

The EL spectra of both the structures $A$ and $\mathrm{R}$ are shown in Figure 9. It can be noticed that the two spectra almost coincide over each other; i.e., there is very minuscule difference between the two spectra. Both the devices show peak wavelength located in red emitter zone at $628 \mathrm{~nm}$. Thus, the proposed CGL has negligible impact on EL spectra relative to red single emitter device. From Luminance versus current density plot studied at $1000 \mathrm{~cd} / \mathrm{m}^{2}$ (Figure 8) it is found that current density of structure $A$ is $6.39 \mathrm{~mA} / \mathrm{cm}^{2}$ which is 1.6 times higher than device $\mathrm{R}$ having current density of $3.84 \mathrm{~mA} / \mathrm{cm}^{2}$. Thus device $\mathrm{R}$ requires less current density than the device A to reach the same luminance. Therefore there is slow efficiency roll-off in device $\mathrm{R}$ than device A which increases with the current density. Thus, tandem devices are more efficient than conventional devices.

Normally it has been known that the turn-on voltage of tandem OLED is over two times greater in contrast to conventional OLED, as in tandem device two EL units are used [9-11]. But from the current density versus voltage graph as shown in Figure 10, the turn-on voltage of device $A$ is found to be $3 \mathrm{~V}$ and device $\mathrm{R}$ is found to be $5.85 \mathrm{~V}$ which is less than two times the turn-on voltage of device A. It should be because of less voltage drop across the proposed CGL, thus showing its effectiveness. From Figure 8, the luminance

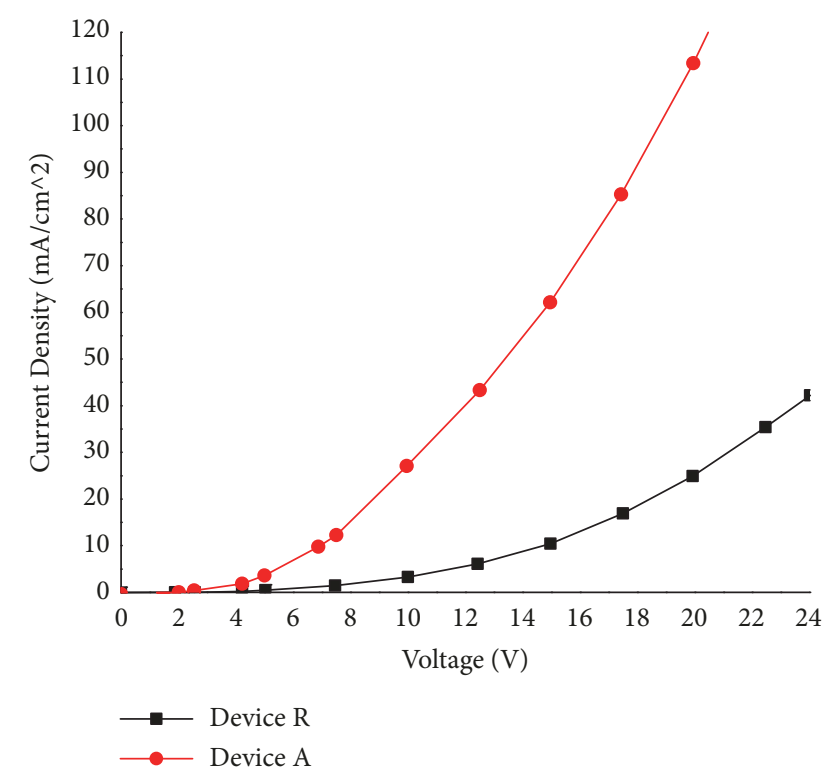

Figure 10: JV plot of devices A and R.

of the tandem device $\mathrm{R}$ is $26,039 \mathrm{~cd} / \mathrm{m}^{2}$ that is 1.66 times the luminance of device $A\left(15,630 \mathrm{~cd} / \mathrm{m}^{2}\right)$ at $100 \mathrm{~mA} / \mathrm{cm}^{2}$. In addition, the current efficiency of device $\mathrm{R}$ is $26 \mathrm{~cd} / \mathrm{A}$ which is almost twice as compared to device A $(15.63 \mathrm{~cd} / \mathrm{A})$. Further enhancement in EQE of device $\mathrm{R}$ is also observed in contrast to device A. The detail EL performances of the device $\mathrm{R}$ and A are concluded in Table 4 .

The difference in the performance of tandem device and single emitter unit device is because of the microcavity effect, interference from light, and many more. The enhancement in performance of tandem devices is because of the CGL that produced almost the same number of free charges as are inoculated by the anode and cathode, thus causing charge carriers balance which leads to reduction in quenching and the plasmonic losses and also increases the microcavity effect. Also, the emission quenching caused by relaxed $\mathrm{CoPc}$ molecules is reduced because of the large distance between emitting unit and CGL. Further, the electric field intensity of tandem device is found to be less in contrast to the single emitter device, thereby reducing the quenching effect caused by electric field in tandem device in contrast to single emitter device. In addition, in tandem devices both the emitting layers are located at the two antinodes so as to take the benefit of increased light output from the microcavity effect [12-15].

To observe the OPV behavior of proposed heterojunction, the UV-vis absorption spectra of $\mathrm{C} 70 / \mathrm{CoPc}$ and the 


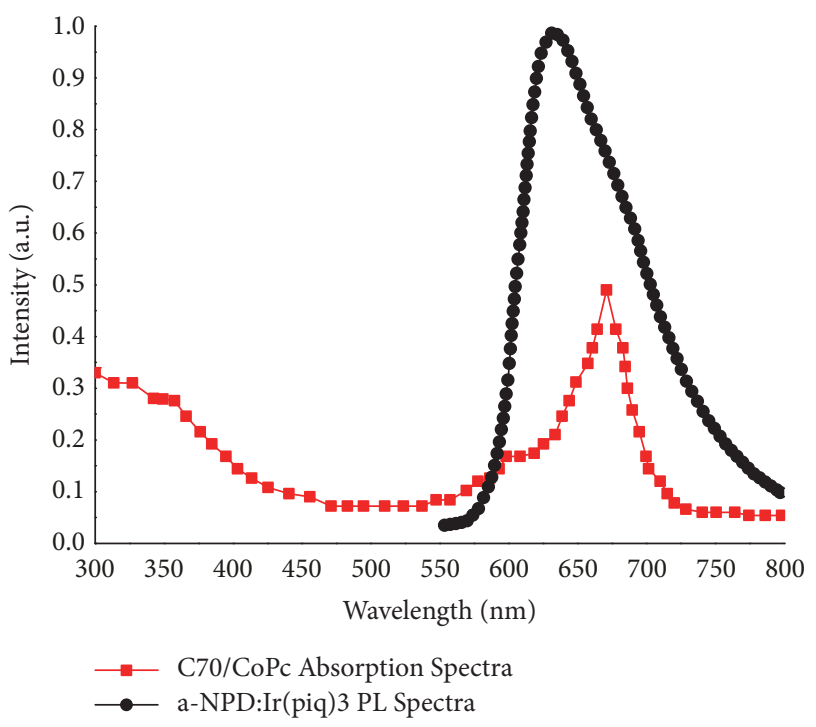

FIgURE 11: Absorption, PL spectra of CGL, and red emitter.

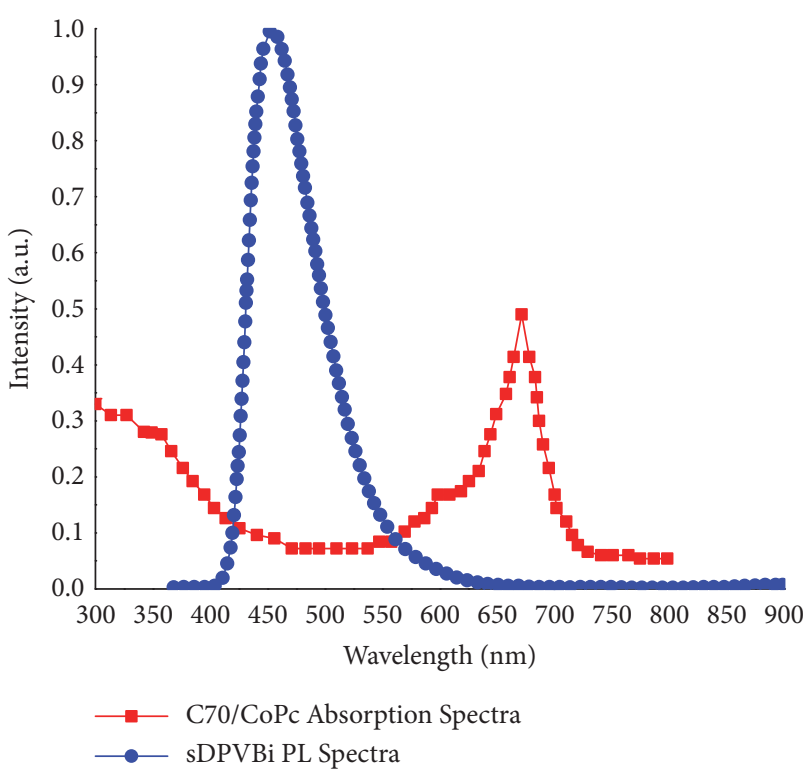

Figure 12: Absorption, PL spectra of CGL, and blue emitter.

photoluminescent spectra of $\alpha$-NPD: $\operatorname{Ir}(\mathrm{piq})_{3}$ are studied. As shown in Figure 11 both spectra overlap each other in the red emitter zone of $600-800 \mathrm{~nm}$. So it can be presumed that the red wasted photons due to surface plasmon and waveguide modes in the emitter can be easily absorbed by $\mathrm{C} 70 / \mathrm{CoPc}$ heterojunction to form excitons and further dissociate them into free charges, thus enhancing the efficiency. A blue tandem device B2 as shown in Table 1 is further designed and simulated to show the organic photovoltaic behavior of the $\mathrm{C} 70 / \mathrm{CoPc}$ heterojunction. From the UV-vis absorption spectra of $\mathrm{C} 70 / \mathrm{CoPc}$ and that of the blue emitter used as shown in Figure 12, it can be seen that two spectra do not coincide; i.e., the peak of the emitter does not fall in the main absorbing area of the $\mathrm{C} 70 / \mathrm{CoPc}$. So, it can be concluded that the proposed CGL is not able to observe the blue photons generated in the emitter.

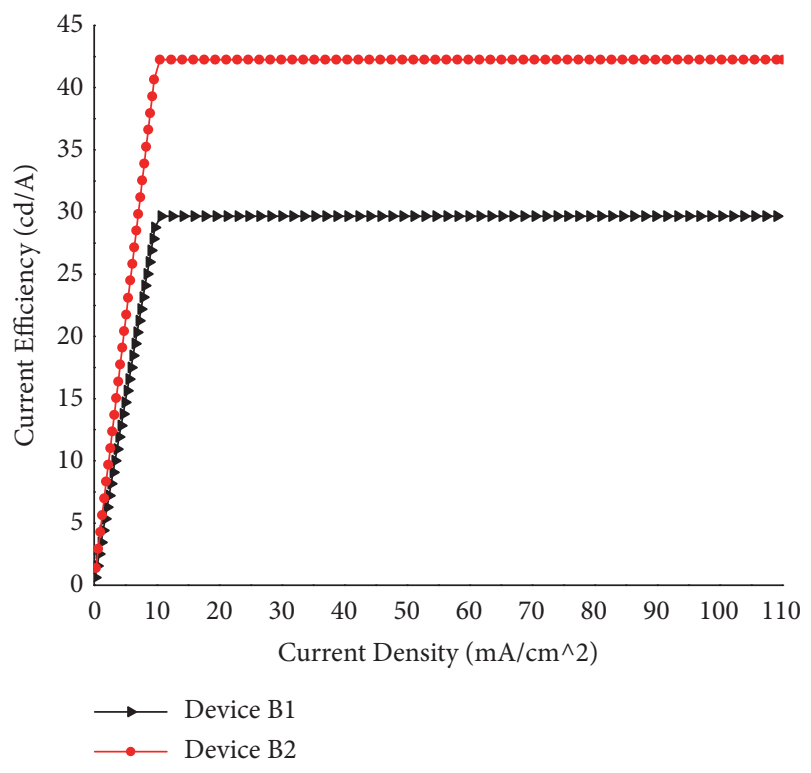

Figure 13: Current efficiency plot of devices B1 and B2.

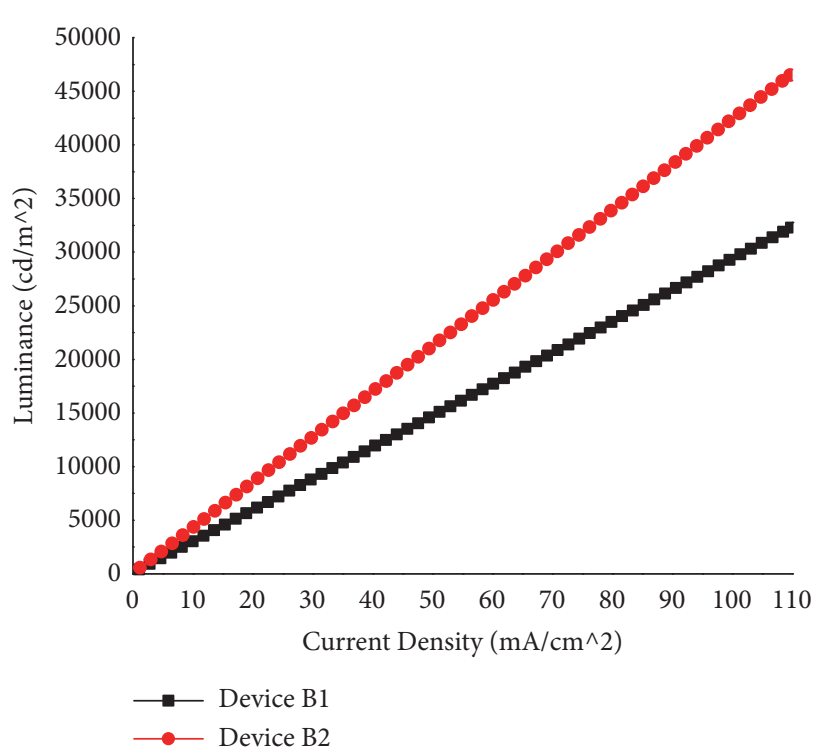

Figure 14: Luminance plot of device B1 and B2.

Also, from Figures 13 and 14, it can be seen that current efficiency and luminance of tandem device B2 $(42.25 \mathrm{~cd} / \mathrm{A}$ and $42250 \mathrm{~cd} / \mathrm{m}^{2}$ ) at $20 \mathrm{~mA} / \mathrm{cm}^{2}$ and $100 \mathrm{~mA} / \mathrm{cm}^{2}$, respectively, is only 1.42 times the current efficiency and luminance of device B1 $\left(29.67 \mathrm{~cd} / \mathrm{A}\right.$ and $\left.29670 \mathrm{~cd} / \mathrm{m}^{2}\right)$ whereas because of the OPV type behavior of device $\mathrm{R}$ which is the absorption of red wasted photons by the proposed heterojunction, the current efficiency of device $\mathrm{R}$ at the same current density is 1.6 times the efficiency of device A. The JV characteristics of device $\mathrm{B} 1$ and $\mathrm{B} 2$ are shown in Figures 15 and 16, respectively. It can be observed that the turn-on voltage of device B2 is about $4.2 \mathrm{~V}$ which is 2.3 times greater than that of device $\mathrm{B} 1$ having turn-on voltage of $1.8 \mathrm{~V}$. On the other hand, from 


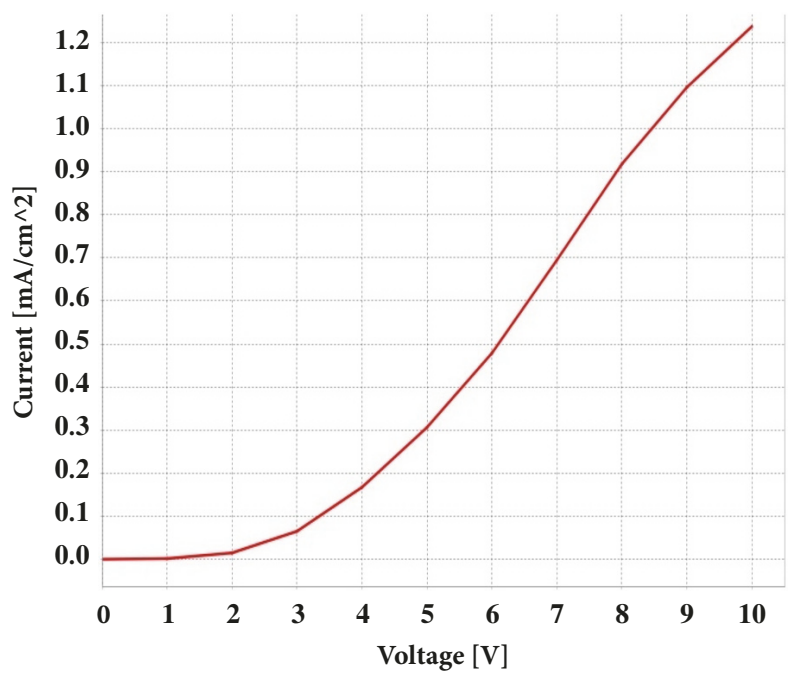

FIgURE 15: JV plot of of device B1.

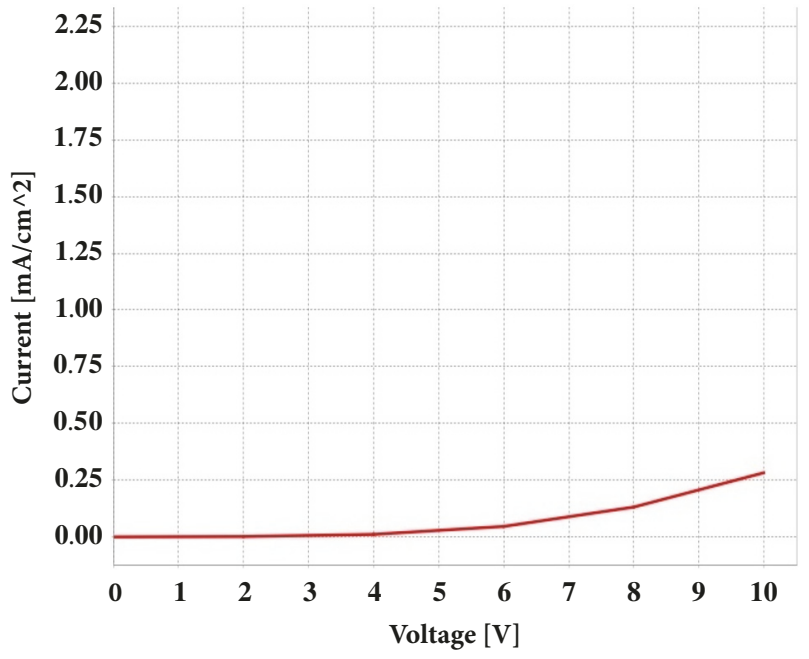

FIGURE 16: JV plot of device B2.

Figure 10, it can be observed that the turn-on voltage of device $\mathrm{R}$ is only 1.9 times greater than that of device A. It is because in device B2, the CGL does not exhibit OPV type behavior, so the excitons are not present in the CoPc layer. So, the charge generation at the low current density is due to the transfer of electrons from HOMO of CoPc to the LUMO of C70 and because of the large energy barrier between the C70 and CoPc interface as depicted in Figure 1, greater value of electric field is needed for the charge carriers transfer, thereby reducing the efficiency and requiring high turn-on voltage.

The basic requirement in CGL is the generation of charges at the CGL interface. Many models have been proposed till date to show the charge generation capability of CGL like Kroger et al. who in [16] have suggested that the charge production capability of interconnector does not depend on temperature. Sun et al. in [17] have demonstrated through JV characteristics the charge production ability of interconnector under reverse bias. In this work, the charge generation

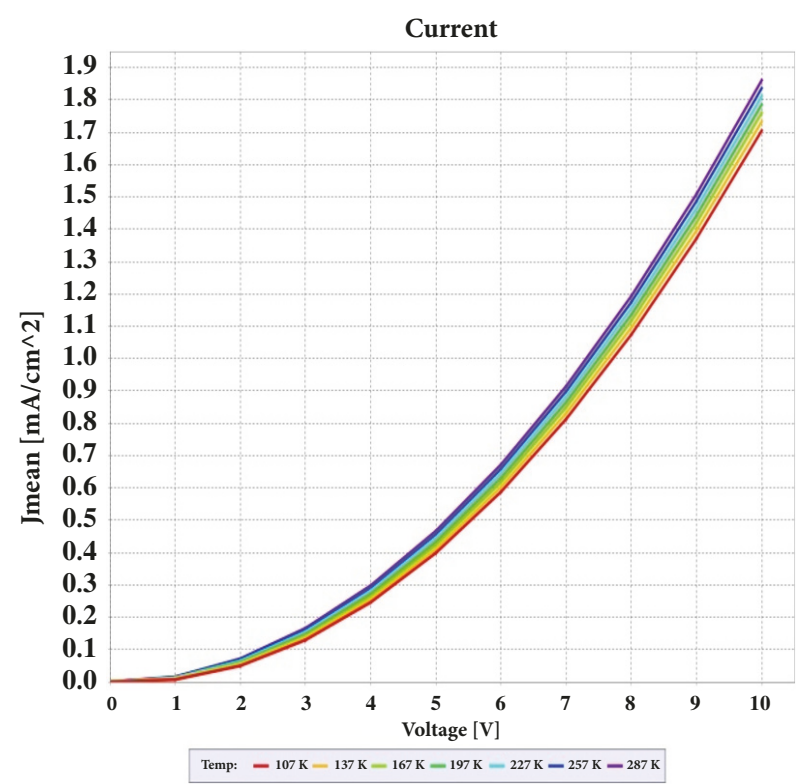

FIGURE 17: JV plot of device $\mathrm{R}$ at various temperatures.

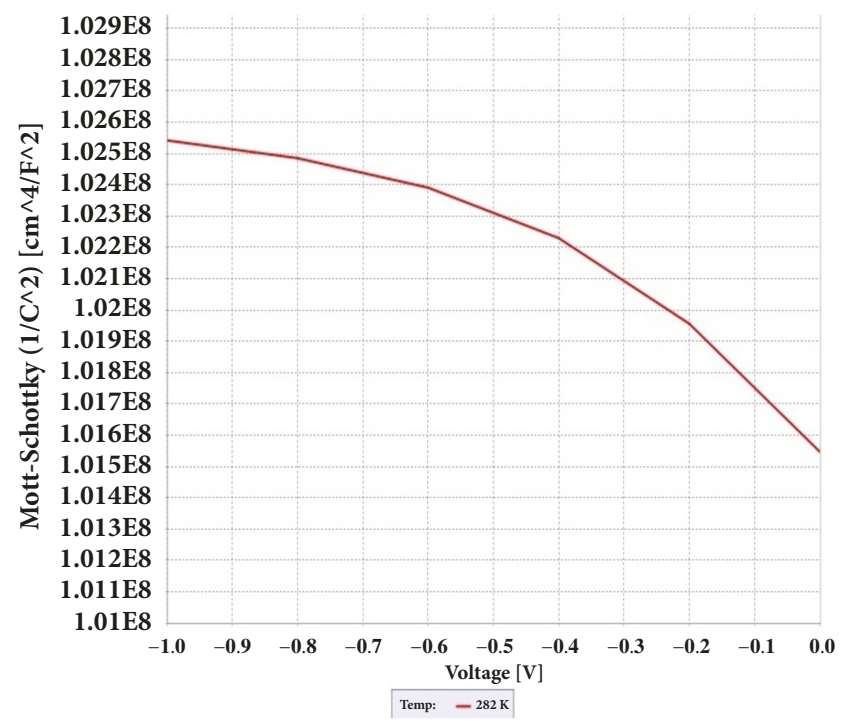

Figure 18: Mott-Schottky plot of device R at 282K.

capability of CGL is explained through J-V and C-V plot of tandem device $\mathrm{R}$ as shown in Figures 17 and 18, respectively. It can be seen that, at about $1.1 \mathrm{~V}$ forward voltage, the current begins to increase; on the other hand correspondingly there is a drastic decrease in the capacitance which can be attributed to the large injection and recombination of charge carriers. Also, at about $1 \mathrm{~V}$ reverse voltage there is critical decrease in capacitance as well as current breakdown which can be attributed to large generation of charge carriers at $\mathrm{C} 70 / \mathrm{CoPc}$ heterojunction [16]. This is because under the reverse voltage, hole and electron transport layers should stop the transport of electrons and holes, respectively. So, the large reverse current in the device $\mathrm{R}$ should be because of the charge carriers production rather than because of the injection by 
anode and cathode under the reverse bias. The entire working process of tandem device can be concluded as follows. At small current density, due to the generation of charges at heterojunction, current efficiency increases rapidly with the increase in luminance of device. Then, the current efficiency becomes invariable, after attaining the maximum height. This is because of the recombination of these generated charges at CGL with the charges inoculated by electrodes in the emissive layer to produce photons. Due to the OPV type behavior, CGL fetches a part of wasted photons from emissive layer to generate more charges and again the whole process repeats causing the slower efficiency roll-off. Thus, this OPV type CGL is very effective and results in longer lifespan of the device.

Further to improve the performance of device $\mathrm{R}$ in terms of efficiency, longer lifespan, and low power consumption and to elucidate microcavity effect for red emitter, DBR substrates consisting of quarter wavelength stack two layers of high refractive index Zirconium Dioxide $\left(\mathrm{ZrO}_{2}\right)$ and low refractive index Silicon Dioxide $\left(\mathrm{SiO}_{2}\right)$ is used. The reflectance of Distributed Bragg Reflector (DBR) structure depends upon variation in the refractive index of layers and number of layer pairs used in the structure. The more the gap and number of pairs are, the greater the reflectance will be. The DBR structures with high reflectance help in achieving highly effective cavity structures and thus help in improving brightness of the device. The optimized quarter wavelength thickness of $\mathrm{ZrO}_{2}$ is found to be $64 \mathrm{~nm}$ by using the formula $\left(\lambda / 4 n_{\mathrm{ZrO}_{2}}=64 \mathrm{~nm}\right.$, where $n_{\mathrm{ZrO}_{2}}=2.45, \lambda=$ $628 \mathrm{~nm})$ and that of $\mathrm{SiO}_{2}$ is found to be $107 \mathrm{~nm}\left(\lambda / 4 n_{\mathrm{SiO}_{2}}=\right.$ $107 \mathrm{~nm}$, where $\left.n_{\mathrm{SiO}_{2}}=1.4575, \lambda=628 \mathrm{~nm}\right)$. Here $\lambda=628 \mathrm{~nm}$ is the peak wavelength of device R. The reflectance (Figure 19) of single pair of $\mathrm{ZrO}_{2}$ and $\mathrm{SiO}_{2}$ is found to be approximately $56 \%$ at $625-628 \mathrm{~nm}$ wavelength. Further enhancement in current efficiency and luminance (Figure 20) at $20 \mathrm{~mA} / \mathrm{cm}^{2}$ and $100 \mathrm{~mA} / \mathrm{cm}^{2}$, respectively, of device $\mathrm{R}$ is observed with the DBR structure which is found to be $31.80 \mathrm{~cd} / \mathrm{A}$ and $31,800 \mathrm{~cd} / \mathrm{m}^{2}$ respectively. This enhancement is due to the constructive interference of light because of DBR structure.

\section{Conclusions}

In this paper, the novel planar organic heterojunction of $\mathrm{C} 70 / \mathrm{CoPc}$ is proposed as planar charge generation layer which shows organic photovoltaic type behavior in red wavelength range from 600 to $800 \mathrm{~nm}$. The advantage of using organic photovoltaic CGL is that they can generate charges and can absorb the wasted photons from emitter to form excitons and dissociate them into free electrons and holes. As a result, there is rather slower efficiency roll-off as compared to other devices. The tandem device exhibits 1.63 and 1.65 times enhanced current efficiency and luminance in contrast to conventional device. Also, remarkable reduction in turnon voltage of the proposed tandem device as compared to other tandem device is observed. The turn-on voltage of tandem device is found to be only 1.9 times greater than that of the single emitter unit device. This remarkable improvement in performance can be attributed to the excellent charge generation, separation ability of interconnector, and excellent

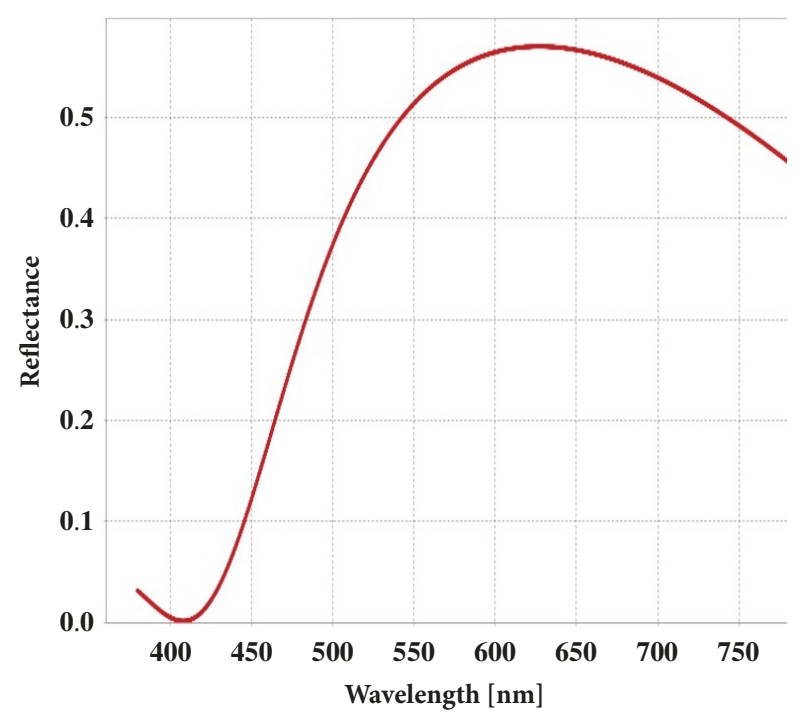

FIGURE 19: Reflectance of DBR structure.

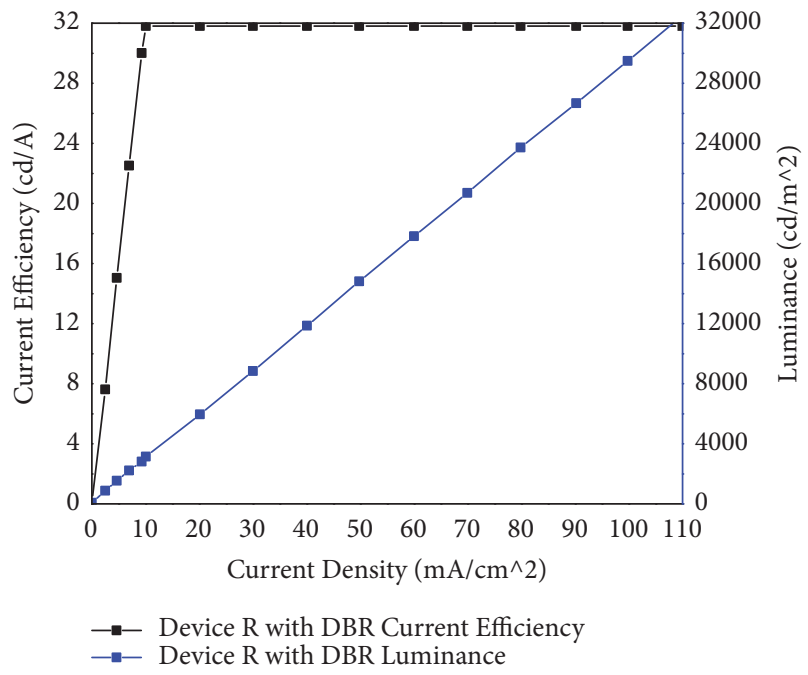

FIGURE 20: Current Efficiency and Luminance plot of DBR structure.

transport capability of $\mathrm{Al} / \mathrm{LiF}$ electron injection layer which can be seen from the great rise of capacitance and current density with voltage. Also, from -J-V and C-V curves it can be confirmed further that the produced carriers are due to the reverse bias current. Further, by inculcating DBR structure of high refractive index $\mathrm{ZrO}_{2}$ and low refractive index $\mathrm{SiO}_{2}$, the performance of tandem device in terms of current efficiency and luminance got enhanced by almost two times in contrast to conventional OLED. Thus, the doping free planar organic heterojunction yields high performance tandem OLED with the low fabrication cost. Also, the proposed work opens the path to explore the behavior of organic photovoltaic heterojunctions for fabricating highly efficient OLEDs.

\section{Conflicts of Interest}

The author declare that there are no conflicts of interest regarding the publication of this paper. 


\section{Acknowledgments}

The author would like to thank Dr. S.S Pattnaik, Director National Institute of Technical Teachers' Training \& Research, Chandigarh, India, and for constant motivation and support throughout this research work.

\section{References}

[1] D. Zhao, H. Liu, Y. Miao et al., "A red tandem organic lightemitting diode based on organic photovoltaic-type charge generation layer," Organic Electronics, vol. 32, pp. 1-6, 2016.

[2] Z. Lü, Y. Wang, X. Li, J. Xiao, and Z. Deng, "Role of MoO3modified organic photovoltaic-type charge generation layer in tandem organic light-emitting diodes," Synthetic Metals, vol. 229, pp. 47-51, 2017.

[3] M. Ramar, P. Tyagi, C. K. Suman, and R. Srivastava, "Enhanced carrier transport in tris(8-hydroxyquinolinate) aluminum by titanyl phthalocyanine doping," RSC Advances, vol. 4, no. 93, pp. 51256-51261, 2014.

[4] S. Altazin, S. Züfle, E. Knapp et al., "Simulation of OLEDs with a polar electron transport layer," Organic Electronics, vol. 39, pp. 244-249, 2016.

[5] J. Yang, Y. Xiao, Y. Deng et al., "Electric-Field-Assisted Charge Generation and Separation Process in Transition Metal OxideBased Interconnectors for Tandem Organic Light-Emitting Diodes," Advanced Functional Materials, vol. 22, no. 3, pp. 600608, 2012.

[6] Y. Chen, Q. Wang, J. Chen, D. Ma, D. Yan, and L. Wang, "Organic semiconductor heterojunction as charge generation layer in tandem organic light-emitting diodes for high power efficiency," Organic Electronics, vol. 13, no. 7, pp. 1121-1128, 2012.

[7] Y. Chen, D. Ma, H. Sun et al., "Organic semiconductor heterojunctions: electrode-independent charge injectors for highperformance organic light-emitting diodes," Light: Science \& Applications, vol. 5, no. 3, pp. e16042-e16042, 2016.

[8] K. L. Mutolo, E. I. Mayo, B. P. Rand, S. R. Forrest, and M. E. Thompson, "Enhanced open-circuit voltage in subphthalocyanine/ $\mathrm{C}_{60}$ organic photovoltaic cells," Journal of the American Chemical Society, vol. 128, no. 25, pp. 8108-8109, 2006.

[9] L. Duan, T. Tsuboi, Y. Qiu, Y. Li, and G. Zhang, "Tandem organic light-emitting diodes with $\mathrm{KBH}_{-} 4$ doped 9,10-bis(3-(pyridin3-yl)phenyl) anthracene connected to the charge generation layer," Optics Express, vol. 20, no. 3, pp. 64-72, 2012.

[10] Y. Deng, J. Wang, Q. Ou et al., "The electro-optic performance and photovoltaic effect of organic devices based on cesium carbonate/Al/molybdenum trioxide intermediate connector," Organic Electronics, vol. 51, pp. 452-457, 2017.

[11] Y. Chen, H. Tian, J. Chen et al., "Highly efficient tandem white organic light-emitting diodes based upon $\mathrm{C} 60 / \mathrm{NaT} 4$ organic heterojunction as charge generation layer," Journal of Materials Chemistry, vol. 22, no. 17, p. 8492, 2012.

[12] Y. Chen and D. Ma, "Organic semiconductor heterojunctions as charge generation layers and their application in tandem organic light-emitting diodes for high power efficiency," Journal of Materials Chemistry, vol. 22, no. 36, pp. 18718-18734, 2012.

[13] L. S. Liao and K. P. Klubek, "Power efficiency improvement in a tandem organic light-emitting diode," Applied Physics Letters, vol. 92, no. 22, pp. 1-3, 2008.

[14] T. Cho, C. Lin, and C. Wu, "Microcavity two-unit tandem organic light-emitting devices having a high efficiency," Applied Physics Letters, vol. 88, no. 11, pp. 1-3, 2006.
[15] C. Xiang, W. Koo, F. So, H. Sasabe, and J. Kido, "A systematic study on efficiency enhancements in phosphorescent green, red and blue microcavity organic light emitting devices," Light: Science \& Applications, vol. 2, no. 6, pp. e74-e74, 2013.

[16] M. Kröger, S. Hamwi, J. Meyer et al., “Temperatureindependent field-induced charge separation at doped organic/ organic interfaces: Experimental modeling of electrical properties," Physical Review B: Condensed Matter and Materials Physics, vol. 75, no. 23, 2007.

[17] H. Sun, Q. Guo, D. Yang, Y. Chen, J. Chen, and D. Ma, "High efficiency tandem organic light emitting diode using an organic heterojunction as the charge generation layer: An investigation into the charge generation model and device performance," ACS Photonics, vol. 2, no. 2, pp. 271-279, 2015. 

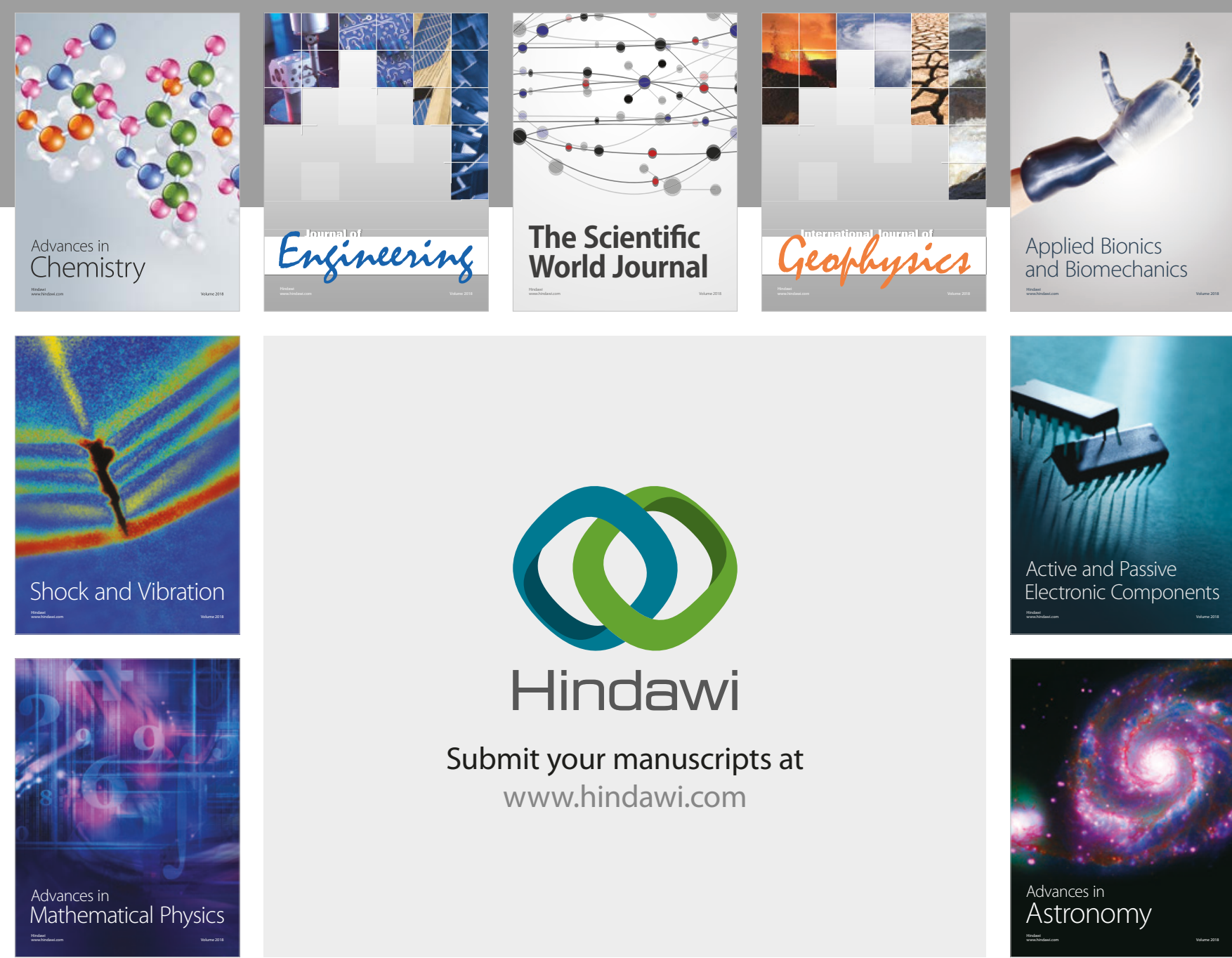

Submit your manuscripts at

www.hindawi.com

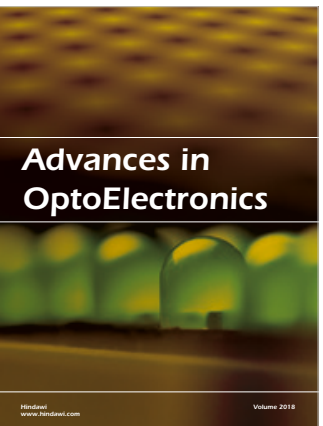

\section{Rotcting Machinery}
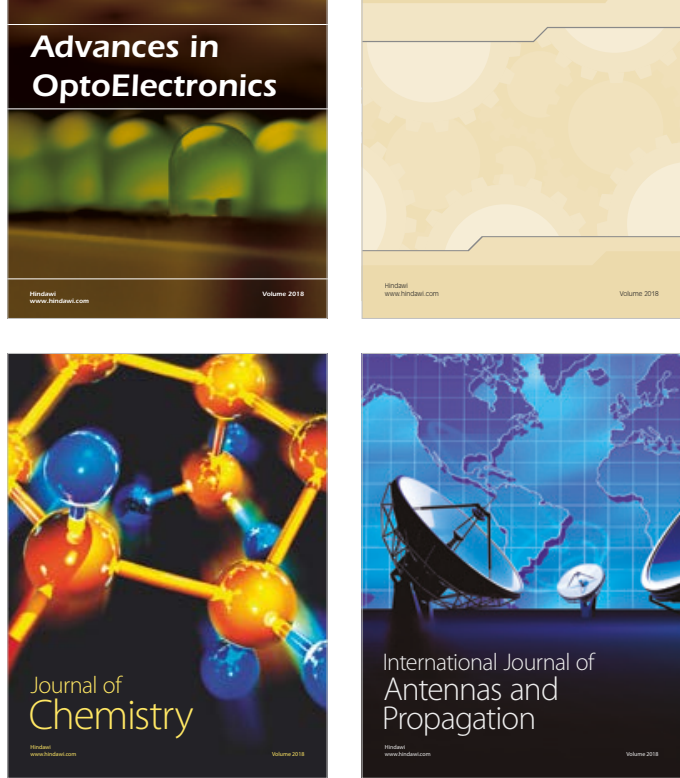

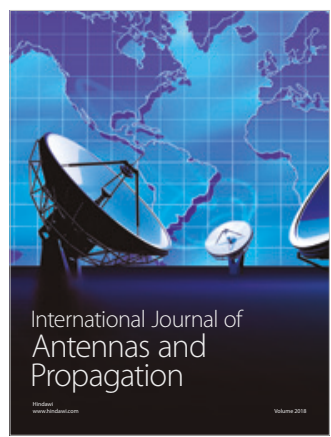

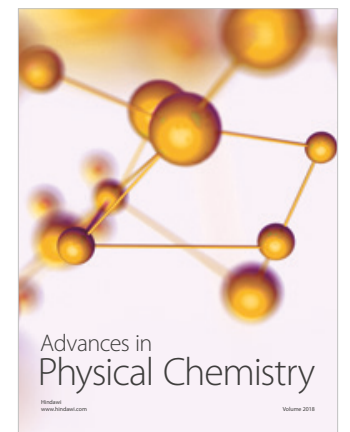

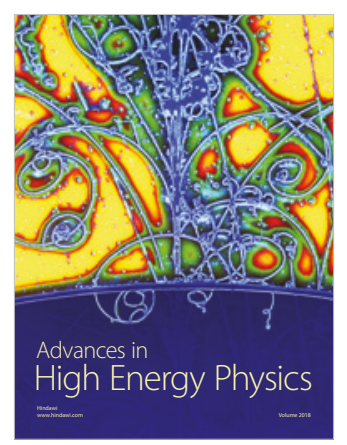

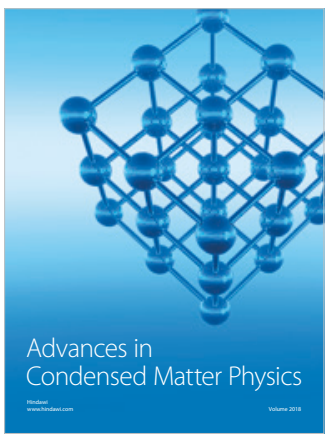

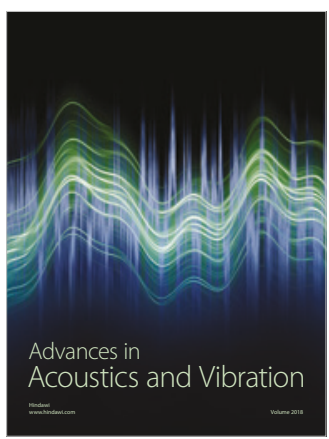

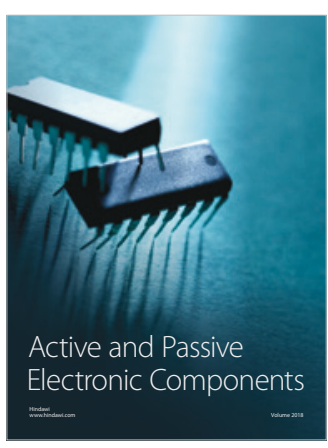
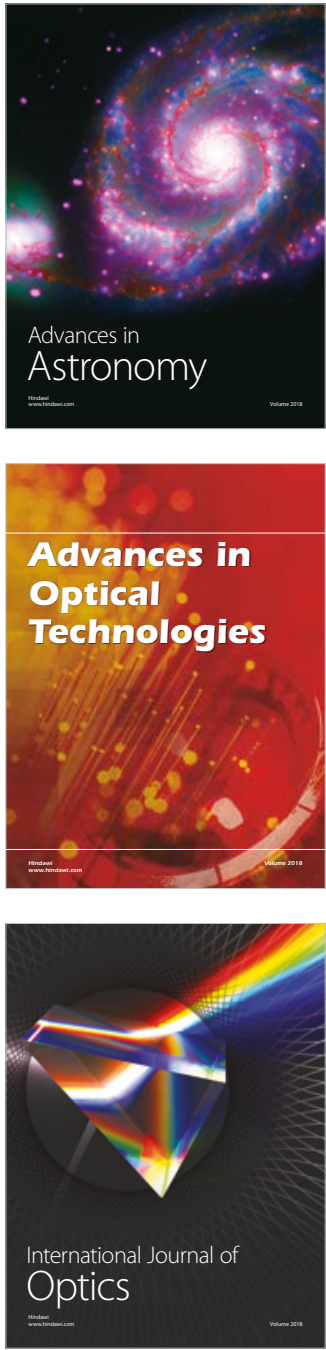